\title{
Sexism experienced by consultant cardiologists in the United Kingdom
}

\author{
Shareen Kaur Jaijee (1) 1,2 Caroline Kamau-Mitchell, ${ }^{3}$ Ghada W Mikhail, 1,4 \\ Cara Hendry 5
} Healthcare NHS Trust, London, UK

${ }^{2} \mathrm{MRC}$, Imperial College London, London, UK

${ }^{3}$ Organisational Psychology, Birkbeck University of London, London, UK

${ }^{4}$ Cardiology, Imperial College London, London, UK

${ }^{5}$ Cardiology, Manchester Royal Infirmary, Manchester, UK

Correspondence to

Dr Shareen Kaur Jaijee, Cardiology, Imperial College Healthcare NHS Trust, London, London, UK;

shareen.k.jaijee@gmail.com

Received 24 July 2020

Accepted 28 January 2021

Published Online First

15 March 2021
${ }^{1}$ Cardiology, Imperial College

Revised 20 January 2021

ABSTRACT

Objectives The aims were to compare the frequency with which male and female cardiologists experience sexism and to explore the types of sexism experienced in cardiology.

Methods A validated questionnaire measuring experiences of sexism and sexual harassment was distributed online to 890 UK consultant cardiologists between March and May 2018. $\chi^{2}$ tests and pairwise comparisons with a Bonferroni correction for multiple analyses compared the experiences of male and female cardiologists.

Results 174 cardiologists completed the survey (24\% female; $76 \%$ male). The survey showed that $61.9 \%$ of female cardiologists have experienced discrimination of any kind, mostly related to gender and parenting, compared with $19.7 \%$ of male cardiologists. $35.7 \%$ of female cardiologists experienced unwanted sexual comments, attention or advances from a superior or colleague, compared with $6.1 \%$ of male cardiologists. Sexual harassment affected the professional confidence of female cardiologists more than it affected the confidence of male cardiologists $(42.9 \%$ vs $3.0 \%)$, including confidence with colleagues (38\% vs $10.6 \%$ ) and patients ( $23.9 \%$ vs $4.6 \%$ ). $33.3 \%$ of female cardiologists felt that sexism hampered opportunities for professional advancement, compared with $2.3 \%$ of male cardiologists.

Conclusion Female cardiologists in the UK experience more sexism and sexual harassment than male cardiologists. Sexism impacts the career progression and professional confidence of female cardiologists more, including their confidence when working with patients and colleagues. Future research is urgently needed to test interventions against sexism in cardiology and to protect the welfare of female cardiologists at work.

\section{Linked InTRODUCTION}

http://dx.doi.org/10.1136/ heartjnl-2020-318057

Check for updates

(c) Author(s) (or their employer(s)) 2021. No commercial re-use. See rights and permissions. Published by BMJ.

To cite: Jaijee SK, KamauMitchell C, Mikhail GW, et al. Heart 2021;107:895-901.
In 2019, the European Union issued the first internationally agreed definition of sexism: 'Any act, gesture, visual representation, spoken or written words, practice, or behaviour based upon the idea that a person or a group of persons is inferior because of their sex'. ${ }^{1}$ This is legally distinct from sexual harassment, which is unlawful. Harassment is defined but not limited to 'engaging in unwanted conduct with the purpose or effect of violating a person's dignity...or creating an intimidating, hostile, degrading, humiliating or offensive environment'. This extends to a person being 'treated unfairly because they have either been submissive or have rejected that conduct'. ${ }^{2}$ Discrimination due to any of the nine protected characteristics, which include pregnancy, maternity and gender, is also unlawful. $^{2}$

Sexism has been reported in the cardiology profession worldwide. In 2005, Timmis et $\mathrm{al}^{3}$ surveyed 62 female cardiology consultants and trainees in the UK and found that $43 \%$ experienced gender bias. In the USA a contemporary study has shown that $66 \%$ of female cardiologists experience discrimination, ${ }^{4}$ and female cardiologists report inhibition of career and opportunities and reduced salary in comparison with their male counterparts. ${ }^{5-7}$ The proportion of female cardiologists varies between $13 \%$ and $15 \%{ }^{48}$ in the UK, Australia and USA. In the UK, $9.4 \%$ of female trainees working in a cardiology specialist training post have experienced or witnessed use of sexist language. ${ }^{10}$ Little is known, however, about the sexism experiences of consultant cardiologists in the UK. To our knowledge this is the first study of its kind, comparing the extent to which UK male and female consultant cardiologists experience sexism and sexual harassment. We hypothesised, consistent with previous evidence, that female cardiologists experience more sexism and sexual harassment at work compared with male cardiologists, perceive more career barriers and carry more domestic responsibilities with less spousal support for childcare. This study will add to research from other countries, showing that female cardiologists face several barriers in their personal and professional life.

\section{METHODS}

The population studied were UK consultant cardiologists. Contact details were obtained from the Royal College of Physicians (RCP), who had consented for release of their contact details, and the Directory of Cardiology (http://cardiodirectory.co.uk), a voluntary database of doctors who are cardiologists. From these, 890 consultant cardiologists' contact details were obtained. This represents $52 \%$ of the total number of consultant cardiologists practising in the UK. A questionnaire was developed (full questionnaire in online supplemental file 1). Questions were adapted from previous studies carried out in the USA, ${ }^{4} 1112$ as well as validated questionnaires to assess perceived organisational support (POS) (Eisenberger's 16-item scale), work-family conflict (WFC) and family-work conflict (FWC) (Netemeyer's 5-item scales), satisfaction with family life (SWFL) (Zabriskie and Ward's modified version of 
the Satisfaction with Life Scale), and professional satisfaction (Hackman and Oldham's Job Diagnostic Survey), which have demonstrated a minimum consistency of a Cronbach's alpha of $0.7 .^{13-16}$ A Likert-style format was used for answers. Some questions invited participants to comment (online supplemental file 2). The Online Surveys platform (Bristol, 2018) was used to distribute the survey. The survey was launched on the online platform from March to May 2018. Participants were contacted via email and sent reminders fortnightly until the closure of the survey.

Outcomes measured included demographics, professional background, POS, WFC and FWC, SWFL and carer responsibilities, professional satisfaction, perceived career advancement, perceived and experienced discrimination, and attitudes to parttime work. Women were compared with men.

\section{Patient and public involvement}

Patients were not involved in the development of the study design.

\section{Statistical analysis}

Data were analysed using IBM SPSS Statistics V.22. Continuous data were analysed using paired t-tests for related samples and independent t-tests for independent samples. For non-parametric data, Wilcoxon signed-rank test was used for related samples and the Mann-Whitney U test for independent samples. Descriptive statistics were used to describe the characteristics of the population and reported either as mean \pm SD or median (IQR). Where appropriate $\chi^{2}$ tests were used to compare differences in responses by women and men, with a Bonferroni correction for multiple analyses. A Pearson's or Spearman's correlation test, depending on normality of data, was used to assess the strength and the direction of relationships between parameters. A twosided $\mathrm{p}$ value of $<0.05$ was considered statistically significant. A multiple regression analysis to predict the impact of gender on sexism experiences, controlling for race and other work settings, was carried out.

\section{RESULTS}

Of 890 email invitations to consultants, 174 consultants completed the survey $(75.9 \%$ male $(n=132)$ and $24.1 \%$ female $(n=42)$, representing a $19.6 \%$ response rate). Women in the sample were significantly younger than men $(\mathrm{p}<0.05)$, with more women aged $40-44$ years $(12.1 \%$ vs $26.2 \%)$ and more men aged $55-59$ years $(22.0 \%$ vs $7.1 \%)$.

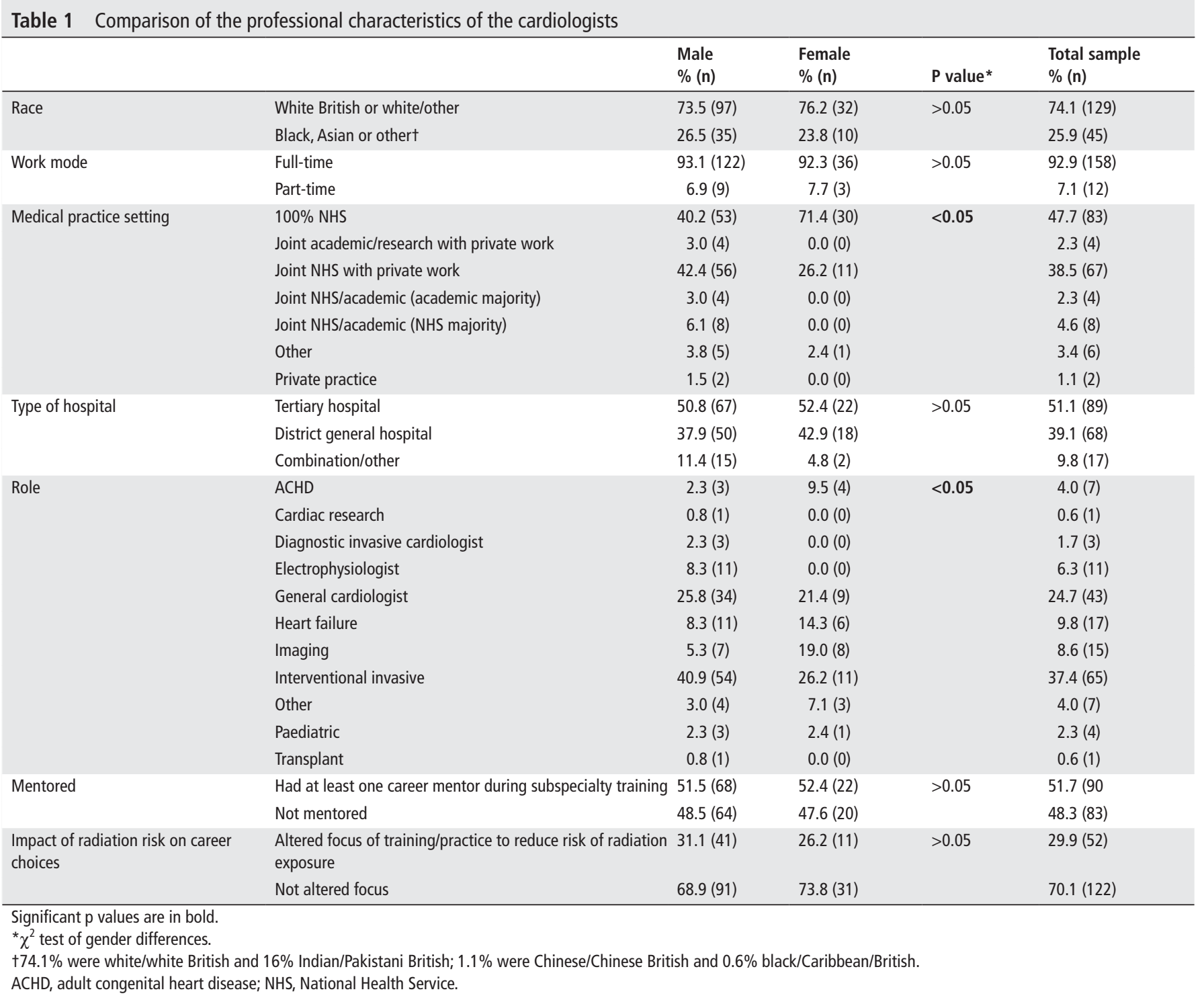




\begin{tabular}{|c|c|c|c|c|c|}
\hline & & $\begin{array}{l}\text { Male } \\
\%(\mathrm{n})\end{array}$ & $\begin{array}{l}\text { Female } \\
\%(\mathrm{n})\end{array}$ & $P$ value* & $\begin{array}{l}\text { Total sample } \\
\%(\mathrm{n})\end{array}$ \\
\hline Marital status & Single, divorced, separated/other & $0.04(7)$ & $0.05(9)$ & & $9.2(16)$ \\
\hline \multirow[t]{2}{*}{ Children } & One or more (biological or adopted) & $91.7(121)$ & $78.6(33)$ & $<0.05$ & $88.5(154)$ \\
\hline & None & $8.3(11)$ & $21.4(9)$ & & $11.5(20)$ \\
\hline \multirow{5}{*}{ Childcare arrangements } & Paid live-in full-time carer & $3.0(4)$ & $11.9(5)$ & 0.038 & $5.2(9)$ \\
\hline & Paid live-out full-time carer & $6.8(9)$ & $21.4(9)$ & 0.016 & $10.3(18)$ \\
\hline & Paid part-time carer & $18.2(24)$ & $33.3(14)$ & 0.053 & $21.8(38)$ \\
\hline & Out of home private care & $8.3(11)$ & $7.1(3)$ & 1.0 & $8.0(14)$ \\
\hline & Out of home institutional care & $28.8(38)$ & $40.5(17)$ & 0.183 & $31.6(55)$ \\
\hline \multirow{3}{*}{$\begin{array}{l}\text { Additional care for weekend } \\
\text { shifts }\end{array}$} & Yes & $44.7(54)$ & $62.1(25)$ & 0.007 & $51.3(79)$ \\
\hline & No & $50.4(61)$ & $18.2(6)$ & & $43.5(67)$ \\
\hline & Other & $5.0(6)$ & $6.1(2)$ & & $5.2(8)$ \\
\hline \multirow{2}{*}{$\begin{array}{l}\text { Primary caregiver (non- } \\
\text { childcare, eg, parent) }\end{array}$} & Yes & $15.9(21)$ & $21.4(9)$ & $>0.05$ & $17.2(30)$ \\
\hline & No & $84.1(111)$ & $78.6(33)$ & & $82.8(144)$ \\
\hline \multirow{5}{*}{$\begin{array}{l}\text { Hours a week spent on } \\
\text { household responsibilities }\end{array}$} & $<5$ & $20.5(27)$ & $9.5(4)$ & $<0.05$ & $17.8(31)$ \\
\hline & $5-10$ & $48.5(64)$ & $26.2(11)$ & & $43.1(75)$ \\
\hline & $11-20$ & $22.0(29)$ & $23.8(10)$ & & $22.4(39)$ \\
\hline & $21-30$ & $8.3(11)$ & $21.4(9)$ & & $11.5(20)$ \\
\hline & $31-40$ & $0.8(1)$ & $19.0(8)$ & & $5.2(9)$ \\
\hline Parental leave impact & $\begin{array}{l}\text { Career or training interrupted by maternity/paternity } \\
\text { leave }\end{array}$ & $7.6(10)$ & $61.9(26)$ & $<0.05$ & $20.7(3$ \\
\hline
\end{tabular}

Significant $\mathrm{p}$ values are in bold.

${ }^{*} \chi^{2}$ test of gender differences.

Table 1 shows that there were no significant gender differences among the cardiologists in the proportions within each race, work mode, hospital type and some career-related variables. Significantly more female cardiologists work solely within the National Health Service (NHS), whereas male cardiologists were more likely to combine NHS and private work. A greater proportion of women than men practise in adult congenital heart disease, imaging and heart failure, whereas more men than women practise interventional cardiology (table 1).

\section{Gender and family life of cardiologists}

Table 2 shows that male cardiologists were significantly more likely to be married, have children, have a spouse that provides all childcare and spend less hours a week on household duties than women. Men were less likely to have a career interruption due to parental leave. Women were more likely to have a paid full-time live-in or live-out child carer, and require childcare for night duty and additional childcare for weekend work.

Women experience significantly more FWC than men (men $22.5 \pm 8.1$ vs women $19.0 \pm 7.8, \mathrm{p}=0.015$ ), where a lower score indicates increased conflict. Women also experience significantly less SWFL (men 14.4 \pm 5.3 vs women 16.7 $\pm 5.3, \mathrm{p}=0.013$ ), where a higher score indicates less satisfaction. Overall, cardiologists find their job meaningful and have a high affective response to their jobs, with no difference between genders. However, among all cardiologists, FWC correlated negatively with job satisfaction $(\mathrm{r}=-0.37, \mathrm{p}<0.05)$, but the correlation was stronger among women $(\mathrm{r}=-0.50, \mathrm{p}<0.05)$ than among men $(r=-0.37, p<0.05)$.

\section{Comparison of experiences of sexism among male and female cardiologists}

Of the respondents 29.9\% reported experiencing discrimination (61.9\% of women vs $19.7 \%$ of men, $\mathrm{p}<0.0001)$. More women reported experiencing discrimination based on gender and parenting responsibilities; $11.5 \%$ reported racial discrimination and $11 \%$ have experienced more than one type of discrimination (table 3).

\section{Experiences of sexism}

Of the women $47.6 \%$ (20) perceived gender biases or obstacles to career success in their environment, vs $12.1 \%$ (16) of men $(p<0.0001)$. Of the women $33.3 \%$ (14) felt that they had been excluded from opportunities for professional advancement based on gender, vs $2.3 \%$ (3) of men $(\mathrm{p}<0.0001)$. When asked whether gender had led to increased opportunities for professional development, fewer men said no $(79.5 \%$ vs $95.2 \%$, $\mathrm{p}=0.022$ ). Table 4 shows examples of sexism experienced or witnessed by male and female cardiologists, with the full list in online supplemental file 2 .

\section{Experiences of sexual harassment}

Of the women $35.7 \%$ (15) have experienced unwanted sexual comments, attention or advances from a superior or colleague, vs 
Table 3 Experiences of discrimination among male and female cardiologists

\begin{tabular}{|c|c|c|c|c|}
\hline & $\begin{array}{l}\text { Male } \\
\% \text { (n) }\end{array}$ & $\begin{array}{l}\text { Female } \\
\% \text { (n) }\end{array}$ & P value* & $\begin{array}{l}\text { Total } \\
\% \text { (n) }\end{array}$ \\
\hline Experienced discrimination (any type) & $19.7(26)$ & $61.9(26)$ & $<0.0001$ & $29.9(52)$ \\
\hline Discrimination relating to parenting & $2.3(3)$ & $31.0(13)$ & $<0.0001$ & $9.2(16)$ \\
\hline Discrimination relating to gender & $2.3(3)$ & $52.4(22)$ & $<0.0001$ & $14.4(25)$ \\
\hline Discrimination relating to race & $11.4(15)$ & $11.9(5)$ & 0.924 & $11.5(20)$ \\
\hline Discrimination relating to religion & $3.8(5)$ & $0.0(0)$ & 0.203 & $2.9(5)$ \\
\hline Discrimination relating to sexual orientation & $0(0)$ & $0(0)$ & $\mathrm{n} / \mathrm{a}$ & $0(0)$ \\
\hline Discrimination relating to age & $1.7(3)$ & $1.1(2)$ & 2.9 & $2.9(5)$ \\
\hline Experienced other type(s) of discrimination & $2.3(4)$ & $3.4(6)$ & 0.006 & $5.7(10)$ \\
\hline
\end{tabular}

Significant $p$ values are in bold.

${ }^{*} \chi^{2}$ test of gender differences.

$\mathrm{n} / \mathrm{a}$, not available.

$6.1 \%(8)$ of men $(\mathrm{p}<0.0001)$. These experiences are summarised in online supplemental file 2 and examples are shown in table 5. Of these, $73.3 \%$ reported this had been a significant problem for them. Of the women $42.9 \%$ felt that the harassment had undermined their confidence as a professional, vs 3.0\% of men $(p<0.0001)$. More women felt that sexual harassment affected them when interacting with colleagues $(10.6 \%$ vs $38 \%$, $\mathrm{p}<0.0001)$ and when conducting professional activities with patients $(4.6 \%$ vs $23.9 \%, \mathrm{p}<0.0001)$.

\section{Career advancement/satisfaction among male and female cardiologists}

Female cardiologists feel that their career advancement is lower than their male peers $(\mathrm{p}<0.0001)$, with $42.8 \%$ (18) of women reporting their advancement was mildly lower, lower or much lower compared with 9\% (12) of men. Overall, $67.2 \%$ of cardiologists feel satisfied with their opportunities to achieve their professional goals, while $25.8 \%$ feel dissatisfied. Women feel significantly less satisfied with their opportunities to achieve their professional goals $(\mathrm{p}=0.009)$, with more women feeling very dissatisfied ( $0 \%$ vs $7.1 \%)$. When asked 'Are career prospects the same for female cardiologists in all cardiology sub-specialities', significantly more women thought they were lower (78.6\% (33) women vs $44.0 \%$ (58) men, $\mathrm{p}<0.05)$, and significantly more men thought they were about the same $(21.4 \%$ (9) women vs 51.5 (68) men, $\mathrm{p}<0.05)$. Of all cardiologists $43.7 \%$ would like the opportunity to work part-time, with no differences between genders; however, $77.6 \%$ of all cardiologists agreed with the statement that 'Working part-time can be perceived by cardiologists as lower status than full time'. When asked 'Cardiologists who work full time are of higher standard than cardiologists who work part-time', significantly more men agreed with the statement or were neutral ( $42.3 \%$ men vs $16.6 \%$ women), while more women disagreed with the statement $(57.7 \%$ men vs $83.4 \%$ women, $\mathrm{p}<0.0001)$. However, $85.7 \%$ of all cardiologists would encourage cardiology to others who seek medical career advice and $84.5 \%$ would choose to become a cardiologist again, with no gender differences.

\section{Correlates of cardiologists' experiences of sexism and the effects of gender}

Total sexism experiences correlated significantly with being female $(r=0.54)$, having had a career interrupted by parental leave $(r=0.21)$, not having children $(r=-0.20)$ and not wanting to choose cardiology again if one had the choice $(r=-0.16)$. The higher the number of total sexism experiences, the more hours a week spent on household responsibilities $(r=0.18)$, the less one felt valued by the organisation they work for $(r=-0.26)$, the more one had FWC $(r=0.32)$ and the less they felt job satisfaction $(r=-0.25)$. Multiple regression showed that gender significantly predicted total sexism experiences even after controlling for race, role in cardiology, working full-time or part-time, hospital type and medical practice setting. The regression model was significant $(F(6,163)=11.42, \mathrm{p}<0.05)$ and the effect of gender was also significant $(t=1.37, \mathrm{p}<0.05)$, whereas no other predictors in the model were significant $(\mathrm{p}>0.05)$.

Table 4 Examples of sexism experienced or witnessed by male and female cardiologists

Examples of sexism reported by "Aware of bias against female cardiology appointments."

male cardiologists

Examples of sexism reported by female cardiologists

"Positive discrimination for female gender."
"(An) assumption that male trainees do not have caring responsibilities."

"Female middle and senior managers appear to hate male doctors."

"I am aware of negative attitudes towards women among some colleagues."

"I think cardiology would be a very difficult choice for a female who wants to start a family. It is not a family friendly specialty."

"I think the gender biases are there, complex and often subconscious there are no women consultants in my unit of $6 . "$

"I am subject to open intimidation and undermining by male colleagues in professional discussions. I feel ignored or not taken seriously, being spoken to in a condescending way; inappropriate banter in clinical meetings."

"Bias towards interventional training of men rather than women."

"Constant undermining of my suggestions."

"Bullying and lack of respect."

"Department doesn't promote women. Male dominated."

"I have been taken off an on-call rota to favour a male colleague who was married with children because the advisor didn't think I needed the money as much as he did- and was told that this was not for discussion."

"... being told not to have any more children (no male colleague has had this experience, as far as I know). Being subjected to unwanted sexual advances, and unacceptable behaviours with "laddish" culture. Invasive questioning about my personal and sex life. Accused of being aggressive if I speak up about an issue or topic." 
Table 5 Experiences of sexual harassment and sexism among male and female cardiologists

\begin{tabular}{|c|c|}
\hline $\begin{array}{l}\text { Examples of sexual harassment } \\
\text { experienced by male cardiologists }\end{array}$ & $\begin{array}{l}\text { "A female has given me unwanted gifts of a sexual nature and has initiated unwanted embraces or other physical contact." } \\
\text { "Female consultant making awkward and unwanted advances." } \\
\text { "Unwanted advances from several colleagues." } \\
\text { "Some inappropriate behaviour from consultant when house officer." }\end{array}$ \\
\hline $\begin{array}{l}\text { Examples of sexual harassment } \\
\text { experienced by female cardiologists }\end{array}$ & $\begin{array}{l}\text { "...Discussions of sexual activities which I did not wish to hear, questioning about my own sexual activities. Inappropriate touching." } \\
\text { "Consultants making suggestive comments and inappropriate attempts at touching." } \\
\text { "Inappropriate comments. Unwanted physical contact. Attempted sexual assault." } \\
\text { "Inappropriate touching, guess the boob size, sexual 'banter."' } \\
\text { "Multiple comments about my breasts, touched inappropriately." } \\
\text { "So many it is impossible to start - I believe this is endemic in cardiology/cardiothoracics as it is in the film industry - i really mean this. }\end{array}$ \\
\hline
\end{tabular}

\section{DISCUSSION}

General Medical Council data reveal that approximately 48\% of registered medical practitioners in the UK are women. ${ }^{17}$ However, $86.7 \%$ of cardiologists are men, the most strongly male-dominated of medical specialties. ${ }^{8}$ Similarly, census data from the RCP reveal that $73 \%$ of all cardiology trainees are male, despite female trainees in medical specialties outnumbering men overall. This suggests that cardiology is unattractive to women.

Data from US interns suggest that decision-making in specialty choice differs between genders; men choose cardiology because they are attracted to it, while women choose not to do cardiology due to deterrent factors. ${ }^{18}$

This is the first study to reveal the rates at which male and female consultant cardiologists experience sexism and sexual harassment, corroborating anecdotal reports ${ }^{19}$ through a quantitative survey of UK consultant cardiologists. Furthermore, this is the first UK study to survey both genders, shedding light on gender differences in UK cardiology practice settings, family responsibilities and aspects of career advancement such as promotion.

\section{Practice settings}

There was a significant difference observed in primary subspecialty role between genders, with more female cardiologists working in non-interventional subspecialties. This parallels US data demonstrating that significantly more men work in procedural subspecialties. ${ }^{4}$ Furthermore, more women practise solely in the NHS and fewer undertake private practice, compared with men, similar to the USA. ${ }^{4}$ This may negatively impact earning potential. Increased family and domestic responsibilities for women and the need to pay for childcare for weekend and night work may be contributory factors to reduced private practice undertaken by women.

\section{Personal and family issues}

Female cardiologists were more likely to be single and to have none or fewer children than male peers. This supports previous studies showing that female cardiologists are less frequently married and more frequently childless, with no change in trend over two decades. ${ }^{40}$ This study demonstrates that women with children are more likely to have paid childcare and require additional childcare for night duty and weekend work, and men more likely to have spouses who care for their children. Women also spend significantly more hours on domestic duties compared with men, experience more FWC and are less satisfied with family life.

\section{Discrimination and sexual harassment}

This study confirms that even in contemporary society, more female cardiologists experience discrimination than men, aligning with a recent US study of cardiologists where $65 \%$ of women and $23 \%$ of men reported discrimination $(p<0.001)^{4}$ and is comparable with studies in other medical professions. ${ }^{21} 22$ Notably, almost $20 \%$ of men also report discrimination, predominantly racial, and $11.5 \%$ of all cardiologists experience discrimination based on race. As $25.9 \%$ of the professions are of ethnic origin, potentially $44 \%$ of ethnic minority cardiologists experience racial discrimination. Of men, $4.6 \%$ experienced discrimination based on parenting and gender.

One-third of women in this study had experienced sexual harassment, concurring with recent US data which identified sexual harassment to be an ongoing problem in medicine. ${ }^{23}$ Additionally, Sinclair et $a l^{10}$ recently reported that $6 \%$ of early-stage trainees in cardiology posts and $15 \%$ of cardiology specialist trainees have experienced or witnessed sexist language. The lower proportions of trainees who reported experiencing sexism may reflect that these doctors are in an earlier stage of their career, are younger in age and have not yet faced pregnancy, maternity leave, parental responsibilities and increased associated domestic responsibilities. Further research on how experiences of sexism change as women progress in their career before and after having children may shed light on these differences.

\section{Gender, career advancement and satisfaction}

Our study demonstrates that female cardiologists report they have fewer opportunities for career advancement, are less satisfied with opportunities to achieve professional goals, perceive gender biases or obstacles to career success by gender, and feel that their career prospects are lower compared with men. This has also been shown in the USA. ${ }^{4}$ Objective evidence has shown that female cardiologists take longer to advance in their careers. ${ }^{7}$ In the UK, female consultants progress more slowly ${ }^{24}$ and are shown less cooperation from other healthcare professionals. ${ }^{22} 25$ This is supported worldwide, where female physicians, particularly those with children, have less career success and have less career support. ${ }^{26}$ Further UK-based research is required to provide objective data to support the perceptions found in our study.

\section{Part-time work}

A significant proportion of cardiologists would like to work part-time; however, majority of the cardiologists (regardless of gender) believe that part-time cardiologists are perceived as of lower status than full-time cardiologists. Furthermore, significantly more men agreed with the statement that 'Cardiologists who work full time are of higher standard than cardiologists who work part-time'. Attitudes to part-time cardiologists have not been extensively studied in this work and require further research. Limited data suggest that part-time work among doctors is not fully accepted and is associated with negative connotations in relation to quality and commitment. ${ }^{27} 28$ 
Key messages

\section{What is already known on this subject?}

- There are very limited data describing sexism experiences of male and female cardiologists in the UK.

- 15 years ago, Timmis et al surveyed 62 female cardiology consultants and trainees in the UK and found that $43 \%$ reported sexism at work.

- A survey by the British Junior Cardiologists Association in 2017 reported that $9.4 \%$ of female trainees (and 3.5\% male trainees) in the UK working in a cardiology post had experienced or witnessed use of sexist language; however, there is no known research assessing the sexism experiences of both male and female consultant cardiologists.

\section{What might this study add?}

- This study presents contemporary data about the sexism experienced by male and female UK consultant cardiologists, showing that $61.9 \%$ of female cardiologists have experienced discrimination of any kind, mostly due to gender and parenting, and this is comparable with that observed 15 years ago by Timmis et al.

- The study presents new evidence that $35.7 \%$ of female cardiologists have been sexually harassed (compared with $6.1 \%$ of male cardiologists).

- The data confirm that female cardiologists are more likely than male peers to experience sexism and that these experiences are more likely to affect their professional confidence when working with patients and colleagues.

- We show that female cardiologists also bear a greater weight in parental or domestic responsibilities.

- To our knowledge, this is the first UK study to assess both male and female consultant cardiologists' experiences of sexism.

\section{How might this impact on clinical practice?}

- More than half of female cardiologists have experienced sexism and many find that it affects their professional confidence when working with colleagues or patients, which might make them unfairly question their own clinical judgement or limit their career aspirations.

- The high prevalence of sexism means that this problem may reduce recruitment into the specialty and this problem may persist for some time to come.

- Urgent interventions are therefore needed to address sexism and sexual harassment in cardiology.

A working group report by the British Cardiovascular Society in 2005 suggested a series of solutions to help encourage recruitment of and support for women in cardiology. ${ }^{3}$ This report, although insightful, was not based on robust evidence and there has been no follow-up report or analysis.

Our study of UK cardiologists shows the need to implement meaningful solutions. Sexism, discrimination and sexual harassment in the UK cardiology consultant population are a real and present problem. Solutions need to look at inherent societal and professional cultural issues. Part-time options are seldom advertised by organisations as they can be perceived as being difficult to arrange. Active support is required for women to advance in to leadership positions and appropriate courses should be delivered in a way that is accessible and attractive. There should be facilities in the workplace and in professional activities to support lactating women and childcare. Women should be empowered to speak out when they encounter sexism or harassment, without fear of repercussion.

\section{Limitations}

The response rate was 19.6\%; hence, there may be a selection bias. However, the response rate is similar to other large-scale surveys of cardiologists in the USA (21\%) ${ }^{4}$ and Italy (21.4\%). Further research should understand why there are low response rates among cardiologists. There were more male than female respondents, which could potentially lead to an underestimation of the problem, but this could reflect the gender distribution in cardiology, where $86.7 \%$ are men. ${ }^{8}$ Furthermore, the proportion of female respondents is in keeping with the proportion of female consultant cardiologists in the UK. Female respondents tended to be younger than male respondents; however, this also represents the physician population where female consultants are overall younger than men. ${ }^{8}$ The time to complete the survey was limited to $20 \mathrm{~min}$, in order to encourage participation, hence this would limit the depth that can be explored.

\section{CONCLUSION}

Sexism in the UK cardiology consultant population is a persistent problem. Significantly more female cardiologists experience gender and parental discrimination, sexual harassment and perceived inhibition of professional advancement in the UK than men. This is an unacceptable position and requires specific targeted initiatives to eradicate negative behaviours and support colleagues in the workplace.

Contributors SKJ: literature search, study design, data collection, data analysis, data interpretation, writing. $\mathrm{CH}$ : study design, manuscript write-up, manuscript review. GWM: study design, manuscript review. CK: study design, manuscript write-up and approval of the final draft.

Funding The authors have not declared a specific grant for this research from any funding agency in the public, commercial or not-for-profit sectors.

Competing interests None declared.

Patient consent for publication Not required.

Ethics approval Ethical approval was obtained from Birkbeck, University of London's Department of Organisational Psychology Ethics Committee.

Provenance and peer review Not commissioned; externally peer reviewed Data availability statement Data are available upon reasonable request. Supplemental material This content has been supplied by the author(s). It has not been vetted by BMJ Publishing Group Limited (BMJ) and may not have been peer-reviewed. Any opinions or recommendations discussed are solely those of the author(s) and are not endorsed by BMJ. BMJ disclaims all liability and responsibility arising from any reliance placed on the content. Where the content includes any translated material, BMJ does not warrant the accuracy and reliability of the translations (including but not limited to local regulations, clinical guidelines, terminology, drug names and drug dosages), and is not responsible for any error and/or omissions arising from translation and adaptation or otherwise.

\section{ORCID iD}

Shareen Kaur Jaijee http://orcid.org/0000-0001-7208-6884

\section{REFERENCES}

1 Europe CoMotSotCo. Recommendation CM/Rec(2019) of the Committee of Ministers to member States on preventing and combating sexism, 2019.

2 Government UK. Equality act 2010. Government UK, 2010.

3 Timmis AD, Baker C, Banerjee S, et al. Women in UK cardiology: report of a working group of the British Cardiac Society. Heart 2005;91:283-9.

4 Lewis SJ, Mehta LS, Douglas PS, et al. Changes in the professional lives of cardiologists over 2 decades. J Am Coll Cardiol 2017;69:452-62.

5 Jagsi R, Biga C, Poppas A, et al. Work activities and compensation of male and female cardiologists. J Am Coll Cardiol 2016;67:529-41.

6 Connolly S, Holdcroft A. The pay gap for women in medicine and academic medicine, 2006. 
7 Modena MG, Lalla M, Molinari R. Determinants of career structure and advancement among Italian cardiologists. An example of segregation and discrimination against women? Eur Heart J 1999;20:1276-84.

8 Trudgill N. Census of consultant physicians and higher specialty trainees, focus on physicians: 2017-8.

9 Segan L, Vlachadis Castles A, Castles V. Women in cardiology in Australia-are we making any progress? Heart Lung Circ 2019;28:690-6.

10 Sinclair HC, Joshi A, Allen C, et al. Women in cardiology: the British Junior Cardiologists' Association identifies challenges. Eur Heart J 2019;40:227-31.

11 Limacher M, Zaher C, Walsh M, et al. The ACC professional life survey: career decisions of women and men in cardiology. J Am Coll Cardiol 1998;32:827-35.

12 Poppas A, Cummings J, Dorbala S, et al. Survey results: a decade of change in professional life in cardiology: a 2008 report of the ACC women in cardiology Council. J Am Coll Cardiol 2008;52:2215-26.

13 Eisenberger R, Huntington R. Perceived organisational support. Journal of Applied Physiology 1986;71:500-7.

14 Netemeyer RG, Boles JS, McMurrian R. Development and validation of workfamily conflict and family-work conflict scales. Journal of Applied Psychology 1996;81:400-10.

15 Diener E, Emmons RA, Larsen RJ, et al. The satisfaction with life scale. J Pers Assess 1985;49:71-5.

16 Hackman R, Oldham GR. The job diagnostic survey: an instrument for the diagnosis of jobs and the Evaludation of job redesign projects. Department of Administrative Sciences, Yale University, 1974

17 Greenaway D. Shape of training: securing the future of excellent patient care, 2020. Available: https://www.gmc-uk.org/-/media/documents/shape-of-training-finalreport_pdf-53977887.pdf
18 Douglas PS, Rzeszut AK, Bairey Merz CN, et al. Career preferences and perceptions of cardiology among US internal medicine trainees: factors influencing cardiology career choice. JAMA Cardiol 2018;3:682-91.

19 Timmis AD, English KM. Women in cardiology: a UK perspective. Heart 2005;91:273-4.

20 Wang TY, Grines C, Ortega R. Women in interventional cardiology: Update in percutaneous coronary intervention practice patterns and outcomes of female operators from the National Cardiovascular Data Registry(R). Catheterization and cardiovascular interventions : official journal of the Society for Cardiac Angiography \& Interventions 2015.

21 Adesoye T, Mangurian C, Choo EK, et al. Perceived discrimination experienced by physician mothers and desired workplace changes: a cross-sectional survey. JAMA Intern Med 2017;177:1033-6.

22 Bruce AN, Battista A, Plankey MW, et al. Perceptions of gender-based discrimination during surgical training and practice. Med Educ Online 2015;20:25923.

23 Choo EK, Byington CL, Johnson N-L, et al. From \#MeToo to \#TimesUp in health care: can a culture of accountability end inequity and harassment? Lancet 2019;393:499-502.

24 Taylor KS, Lambert TW, Goldacre MJ. Career progression and destinations, comparing men and women in the NHS: postal questionnaire surveys. BMJ 2009;338:b1735.

25 Jefferson L, Bloor K, Spilsbury K. Exploring gender differences in the working lives of UK hospital consultants. J $R$ Soc Med 2015;108:184-91.

26 Buddeberg-Fischer B, Stamm M, Buddeberg C, et al. The impact of gender and parenthood on physicians' careers--professional and personal situation seven years after graduation. BMC Health Serv Res 2010;10:40.

27 Federation. MWs. making part-time work, 2008.

28 Lugtenberg M, Heiligers PJM, de Jong JD, et al. Internal medicine specialists' attitudes towards working part-time: a comparison between 1996 and 2004. BMC Health Serv Res 2006;6:126. 